\title{
Prospective and Comparative Assessment of the Eco-Compatibility of Materials
}

\author{
Hans Warlimont* \\ Leibniz Institute for Solid State and Materials Research Dresden, 01069 Dresden, Germany
}

A new and simple concept is proposed for the systematic and quantitative assessment of the technical, economic and ecological aspects of the ecological compatibility of materials and products. This concept can serve for prospective accounting of eco-compatibility in research and development, and for comparisons of alternative technological solutions. It is based on considering six stages of the life cycle and six efficiency parameters for each stage. The ensuing matrix elements can be selected for qualitative or quantitative analysis. The elementary quantitative treatment is based on suitably defined efficiency parameters. This concept alleviates the treatment of a complete life cycle analysis and inventory computation and is particularly useful when a simple and yet concise insight into selected aspects of eco-compatibility of a material or product is required. Economical aspects are introduced regarding minimum energy and material requirements and as a cost difference parameter in comparative treatments. Examples are given to demonstrate the appropriate selection of aspects to be analysed for a particular assessment and to introduce the specific formulation of pertinent efficiency parameters. Thus, the simplicity and transparency of the method and its results is demonstrated.

(Received January 27, 2003; Accepted March 7, 2003)

Keywords: eco-compatibility, eco-efficiency parameters, life cycle analysis, technical compatibility, economic compatibility, ecological compatibility

\section{Introduction}

Improvement of ecological compatibility, eco-compatibility (also called eco-design, design for environment, life-cycle design) is an essential target in recent public and industrial development policies. In the design of new materials, products and processes optimisation of eco-compatibility is added to the common criteria of technical performance and economic viability. The basic motivation for the present concept is to provide a simple and effective tool for combining technical, economic and ecological aspects. In particular it is considered how a materials scientist and engineer can deal prospectively with the technical, economic and ecological aspects in development. In so far the concept is a tool for life-cycle engineering. But it is mainly intended to be a tool which simplifies the analysis and clarifies the terms for improvement of eco-compatibility in scientifictechnical, economic-industrial as well as in socio-political contexts.

Inherent complexity impedes the simultaneous, prospective, and quantitative treatment of technical, economical and ecological aspects of a new material, product or process in a compatible framework. Traditionally, ecological assessments have started with considerations of damage caused by emissions and waste disposal, i.e. by an impact analysis. But even a staunch environmentalist like Ernst Ulrich von Weizsäcker conceded recently that "it is probably better to start from the generation of benefits than from the avoidance of damage". 1) The concept of a combined technical-economic-ecological efficiency analysis is presented here as a holistic but simplified engineering approach. The essence of the present concept is to provide a systematic structure to the problem and an elementary, yet quantitative treatment of individual elements or a limited number of compounded elements which are judiciously selected to treat a particular

*Present address: DSL Dresden Material-Innovation, Helmholtzstrasse 20, 01069 Dresden, Germany. task of development, improvement, comparison and the like. A short, qualitative description of the concept has been given in a previous paper. ${ }^{2)}$

International standard ISO $14040^{3)}$ states that "life cycle assessment typically does not address the economic or social aspects of a product". Other recent concepts, however, include economic aspects deliberately. Similarly, more general treatises such as the monograph Natural Capitalism ${ }^{4)}$ deal with combinations of ecological and economic aspects. More fundamental treatises such as an approach to life cycle assessment based on the minimisation of entropy production (and its rate) $)^{5)}$ is tacit about economic issues as such. But by stressing energy efficiency und matter efficiency it implicitly includes economic optimisation as well.

The present concept has arisen from two convictions of the author: 1. the interest in personal and corporate gains in the economic process are the strongest and most persistent motivations to strive, also, for ecological efficiency, 2 . comprehensive and systematic prospective development work rather than post factum analysis and remediation are the appropriate engineering approach to attaining ecologically compatible and economically successful solutions.

The concept of "Ecomaterials", 6) initiated in Japan, has provided a decisive impact on considering the eco-compatibility of materials systematically and in a broader context. However, it has remained an open question how an "ecomaterial" should be defined and developed. Therefore, it is useful to recall that materials are usually integral substances of products and of their environmental impact during their life cycle. Consequently, an assessment of ecocompatibility of any single material as such without taking its use in a particular product and its application into account does not lead to a meaningful assessment and comparison. Systematic materials selection among existing materials under basic property aspects has been pioneered by Ashby. ${ }^{7)}$ The inclusion of ecological aspects is supported by various recent examples and useful overviews, e.g., ${ }^{8)}$ and numerous data banks. However, comparing different materials for use 
in a product is usually associated with considering simultaneously the necessity to newly design or redesign the part or product. This can make LCA treatments very cumbersome, time-consuming, expensive and uncertain in their results for comparing two development opportunities quantitatively unless they happen to pertain to a range of products for which LCI data and LCA design algorithms are available already. Simplified LCA concepts are coming up as the field of eco-balance studies and tools is evolving. ${ }^{9)}$ In the real industrial world ecological compatibility analyses regarding materials and products make no sense unless they are quick, transparent, and are combined with economical analyses. The present concept provides a tool for this kind of approach.

\section{The Concept}

The concept of technical-economic-ecological efficiency analysis has been developed by the author recently and was published briefly first with reference to a new product and process he has developed. ${ }^{2)}$ Basically it treats of the life cycle of material and product in terms of six specifically formulated stages:

- Comprehensive design of materials and parts

- Production of materials and parts

- Comprehensive design of product

- Manufacturing of product

- Application of product

- Disposal and recycling of materials and parts.

It can be seen that these definitions do not deviate fundamentally from those used in similar concepts of life cycle assessment. However, the first and third stages are given a particular and uncommon content here because they imply a prospective analysis and application of eco-compatibility criteria in the design- or redesign-phases of materials and products. The aspect of transport (of material, product) has been omitted deliberately as it is important for bulky products only. But it will be seen, that its inclusion in the present concept poses no problem.

The stages of the life cycle are analysed in the three general categories: technical efficiency, resource efficiency, and environmental efficiency. Each of these is subdivided, in turn, into two "target categories" of development such that six categories (aspects) of evaluation result altogether:

- Maximum physical performance

- Optimum technical performance

- Minimum energy requirement

- Minimum material resources

- Minimum health hazards

- Minimum emissions and wastes

in each stage of the life cycle.

As a seventh target category a differential cost assessment is foreseen and will be dealt with in a future account of this concept. Since the internal cost structure and accounting practice of companies may vary in wide limits an objective full cost calculation will normally be impossible. Therefore, a limitation of the assessment of cost effects to the immediate cost difference in considering specific individual improvements or alternatives will be most practicable. ${ }^{10)}$

The core of the present concept is a matrix representation: the rows represent the different stages of the life cycle of a product; the columns correspond to the six target categories such that they are attributable to each stage of the cycle.

Table 1 shows this matrix containing the 36 elements which are the "aspects" of evaluation in this concept. They are numbered for reference. The matrix is designed to subdivide the points of analysis and action in the framework of technical-economic-ecological efficiency in a systematic way and to a reasonable level of detail. Each matrix element should be considered to require a statement, in qualitative or quantitative terms, as to which goals a new product is achieving or, by comparison, as to which features of an improved or different product supersede a present version regarding eco-compatibility. It should be noted that there are additional interrelations between the matrix elements (e.g., if energy is saved, emissions are reduced etc.). They are not dealt with here. The first two columns are the aspects to be dealt with in the development process the remaining columns represent the effects to be optimised to increase ecocompatibility.

Table 1 Technical-economic-ecological efficiency aspects of materials and products.

\begin{tabular}{|c|c|c|c|c|c|c|}
\hline \multirow[b]{2}{*}{ Stage in the life cycle } & \multicolumn{2}{|c|}{ Technical efficiency } & \multicolumn{2}{|c|}{ Resource efficiency } & \multicolumn{2}{|c|}{ Environmental efficiency } \\
\hline & $\begin{array}{c}\text { Maximum } \\
\text { physical } \\
\text { performance }\end{array}$ & $\begin{array}{c}\text { Optimum } \\
\text { technical } \\
\text { performance }\end{array}$ & $\begin{array}{c}\text { Minimal } \\
\text { energy } \\
\text { requirement }\end{array}$ & $\begin{array}{l}\text { Minimal } \\
\text { material } \\
\text { resources }\end{array}$ & $\begin{array}{c}\text { Minimal } \\
\text { health } \\
\text { hazards }\end{array}$ & $\begin{array}{c}\text { Minimal } \\
\text { emissions } \\
\text { and wastes }\end{array}$ \\
\hline $\begin{array}{l}\text { Comprehensive design } \\
\text { of materials and parts }\end{array}$ & 1.1 & 1.2 & 1.3 & 1.4 & 1.5 & 1.6 \\
\hline $\begin{array}{c}\text { Production } \\
\text { of materials and parts }\end{array}$ & 2.1 & 2.2 & 2.3 & 2.4 & 2.5 & 2.6 \\
\hline $\begin{array}{l}\text { Comprehensive design } \\
\text { of product }\end{array}$ & 3.1 & 3.2 & 3.3 & 3.4 & 3.5 & 3.6 \\
\hline $\begin{array}{l}\text { Manufacture } \\
\text { of product }\end{array}$ & 4.1 & 4.2 & 4.3 & 4.4 & 4.5 & 4.6 \\
\hline $\begin{array}{l}\text { Application } \\
\text { of product }\end{array}$ & 5.1 & 5.2 & 5.3 & 5.4 & 5.5 & 5.6 \\
\hline $\begin{array}{l}\text { Disposal and Recycling } \\
\text { of materials and parts }\end{array}$ & 6.1 & 6.2 & 6.3 & 6.4 & 6.5 & 6.6 \\
\hline
\end{tabular}




\section{Efficiency Parameters}

The appropriate definition of efficiency parameters is decisive for the usefulness of the evaluation procedure for eco-compatibility. The quantities must be meaningful both as individual quantitative indicators as well as in compounded form if a comprehensive evaluation or comparison is sought. In the basic ecomaterials concept eco-efficiency is defined as: ${ }^{11)} \eta_{\mathrm{EE}} \equiv$ (service)/(life-cycle environmental burden). This formulation does not lend itself easily to compute and demonstrate the effect of individual or compounded quantitative measures for increasing eco-compatibility of a material or a product. Therefore, the efficiency parameters attributed to the six categories of evaluation according to the above matrix are defined as follows:

$$
\begin{array}{llll}
\text { Physical Performance : } & \eta_{\mathrm{TP}}=\frac{\text { physical property value actually attained } P_{\text {act }}}{\text { ultimate physical property limit } P_{\text {lim }}} & P_{\text {act }}<P_{\text {lim }} \\
\text { Technical Performance : } & \eta_{\mathrm{TT}}=\frac{1}{n} \sum_{i=1}^{i=n} \frac{\text { minimal technical property } i \text { value specified } T_{i, \text { spec }}}{\text { technical property } i \text { value actually attained } T_{i, \text { act }}} & T_{i, \text { spec }}<T_{i, \text { act }} \\
\text { Energy Efficiency : } & \eta_{\mathrm{RE}}=\frac{\text { minimal energy required } E_{\text {min }}}{\text { energy actually used } E_{\text {act }}} & E_{\text {min }}<E_{\text {act }} \\
\text { Material Efficiency : } & \eta_{\mathrm{RM}}=\frac{\text { minimal mass of material required } M_{\text {min }}}{\text { mass of material actually used } M_{\text {act }}} & M_{\text {min }}<M_{\text {act }} \\
\text { Health Hazards : } & \eta_{\mathrm{EH}}=\frac{\text { actual value of toxicity attained } V_{\text {act }}}{\text { limiting value of toxicity specified } V_{\text {spec }}} & V_{\text {act }}<V_{\text {spec }} \\
\text { Emissions, Wastes : } & \eta_{\mathrm{EE}}=\frac{\text { actual amount of emission/waste } W_{\text {act }} \text { attained }}{\text { limiting amount of emission/waste specified } W_{\text {spec }}} & W_{\text {act }}<W_{\text {spec }}
\end{array}
$$

For the technical efficiency parameters $\eta_{\mathrm{TP}}$ and $\eta_{\mathrm{TT}}$ the limiting values in eqs. (1) and (2) are comparatively easy to define. The limiting values for the resource efficiency parameters $\eta_{\mathrm{RE}}$ and $\eta_{\mathrm{RM}}$ in the eqs. (3) and (4) are frequently known from the technical literature and data collections, especially for the production stage. In other cases they may have to be calculated or estimated. LCI data may be available for specific cases but should be used with the usual precautions as to the quality and possible bias of the source. For the environmental efficiency parameters $\eta_{\mathrm{EH}}$ and $\eta_{\mathrm{EE}}$ according to eqs. (5) and (6) a number of different specifications of limiting values may be applicable depending on the case under consideration: either effective limits such as physical, analytical, biological and technical limitations or regulatory limits such as specifications by law, regulation, technical standard, technical specification and the like. It should be noted that eqs. (5) and (6) have been formulated such that the values actually attained lie below the limiting maximum values specified. If this is not the case and the actual value exceeds the specified limit, the efficiency parameter is the inverse of the ratio shown above and can be used as a measure of approach to the specified value.

It is possible to compound the efficiency parameters if a set of several aspects is to be considered as a characteristic figure of merit. Thus, the potential progress in improvement of a given material or process can be quantified, or the use of different materials or products can be compared. It should be noted, however, that the weight introduced by a particular efficiency parameter into the weighted average may not necessarily reflect its importance in the technical solution and its eco-efficiency. Therefore, compounded efficiency parameters may be defined in two ways: either by simply computing the effective average $\eta_{\mathrm{e}}$ of a set of $n$ selected efficiency parameters $\eta_{i}$

$$
\eta_{\mathrm{e}}=\frac{1}{n} \sum_{i=1}^{i=n} \eta_{i} ;
$$

the technical performance efficiency $\eta_{\mathrm{TT}}$, eq. (2), is an example, if more than one property is taken into account; or by computing a weighted average $\eta_{\mathrm{w}}$ including rating or weighting factors $0<k_{i}<1$ for each of the selected efficiency parameters $\eta_{i}$

$$
\eta_{\mathrm{w}}=\frac{1}{n} \sum_{i=1}^{i=n} k_{i} \eta_{i} .
$$

This inclusion of rating or weighting factors - albeit in other forms of operational definitions of eco-compatibility parameters - is used widely in ecological analyses. But as this introduces a subjective component, critical evaluations of the LCA method ${ }^{11)}$ are finding that weighting factors should not be employed. If weighting factors are used at all in applications of the present concept it is only justifiable if they are based on a quantitative arguments which can be recalculated objectively. This is usually not the case.

\section{Examples}

The subsequent examples are not meant to convey a special insight into the technologies referred to but rather to demonstrate the simplicity, usefulness and relevance of the assessment and formulation of efficiency parameters according to the present concept.

Emissions from aluminium production. In aluminium production the emission of the polyfluorocarbon (PFC) or "greenhouse" gasses $\mathrm{CF}_{4}$ (6500 times $\mathrm{CO}_{2}$ equivalent) and 


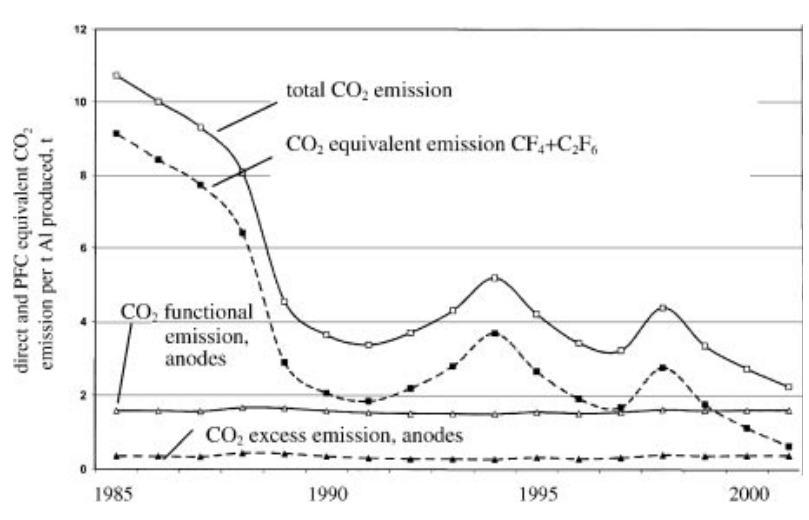

Fig. 1 Reduction of direct and equivalent $\mathrm{CO}_{2}$ emissions by automatic control measures to reduce the number and duration of anode effects in aluminium electrolysis. ${ }^{12)}$

$\mathrm{C}_{2} \mathrm{~F}_{6}$ (9200 times $\mathrm{CO}_{2}$ equivalent) is a problem of lacking eco-efficiency. This emission occurs along with the so-called "anode effect" during electrolytic reduction of $\mathrm{Al}_{2} \mathrm{O}_{3}$ to $\mathrm{Al}$. The anode effect is a sudden rise of the potential in the cryolite salt electrolyte from the usual $4.3 \mathrm{~V}$ to $\geq 25 \mathrm{~V}$. This leads to a release of the polyfluorocarbon gasses, PFCs. A recent report about the improvement of the technical performance in an $\mathrm{Al}$ smelter in the course of 15 years shows that the emissions were drastically reduced, Fig. 1. ${ }^{12)}$

In terms of our analysis the technical improvement of performance in production is associated with matrix element 2.2 and the solution pertains to reduction of emissions in production, i.e. matrix element 2.6. The solution consists of an automatic control of the $\mathrm{Al}_{2} \mathrm{O}_{3}$ level in the bath and other technical measures which result in a drastic reduction of the number and length of the anode effects occurring. The quantitative evaluation can be formulated in this case as follows: the target is to reduce the total emissions from initial $9.1 \mathrm{t} \mathrm{CO}_{2}$ equivalent polyfluorocarbon gas emission per $\mathrm{t} \mathrm{Al}$ produced to as low as $0.4 \mathrm{t} \mathrm{CO}_{2}$ emission per $\mathrm{t} \mathrm{Al}$ produced which is the unavoidable level of $\mathrm{CO}_{2}$ excess emission of the carbon anodes. The actual amount of residual emission achieved is $0.6 \mathrm{t} \mathrm{CO}_{2}$-equivalent per $\mathrm{t} \mathrm{Al}$ produced. Thus, the initial efficiency parameter pertaining to excessive emission was $\eta_{\mathrm{EEi}}=0.4 / 9.1=0.044$ and the final efficiency of emission control achieved was $\eta_{\mathrm{EEf}}=0.4 / 0.6=0.67$. This shows the drastic improvement achieved.

Aluminium recycling for beverage cans. The recycling rate of beverage cans made of aluminium in Europe amounts to about $45 \%$. It is well known that scrap of $\mathrm{Al}$ beverage cans can be recycled back directly into cans because the specific alloys (can body stock 3004; can end stock 5182) can be recycled into $\mathrm{Al}$ sheet of equivalent quality. We wish to assess the increase in eco-compatibility in terms of energy efficiency if the recycling rate is raised to $100 \%$.

To this end a recent study of the German aluminium industry $^{13)}$ and a more detailed LCI study of the Japan Aluminium Association ${ }^{14)}$ are very helpful regarding energy consumption figures. The energy consumption in the manufacturing of can body stock from primary aluminium is $165 \mathrm{GJ} / \mathrm{t}$ whereas it is only $30 \mathrm{GJ} / \mathrm{t}$ if $100 \%$ secondary aluminium, i.e. scrap, is used which is considered to be the ultimate technical limit in this context.

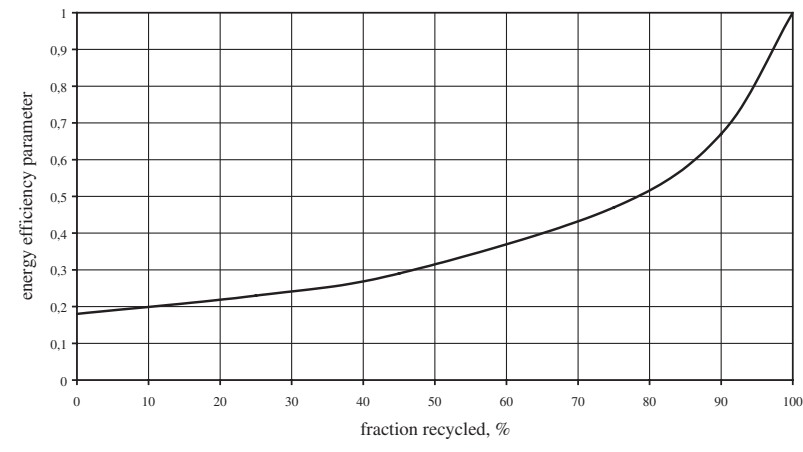

Fig. 2 Dependence of energy efficiency of recycling on the percentage of recycled $\mathrm{Al}$ can scrap.

In terms of the eco-compatibility analysis we are attributing the recycling rate to the aspect optimum technical performance in application of the product, i.e. matrix element 5.2. The relevant target property is energy efficiency resulting from the application in terms of collection rate, i.e. matrix element 5.3 is addressed. If the collection rate of $100 \%$ is set as ultimate technical limit, then the energy efficiency of the present $45 \%$ collection rate is $\eta_{\mathrm{RE}}=30 /(0.45 \cdot 30+0.65$. $165)=0.29$ compared to $\eta_{\mathrm{RE}} 30 / 30=1$, by definition, if all cans were collected and recycled into can stock. For reference it may be mentioned that making cans of primary $\mathrm{Al}$ only would correspond to an energy efficiency of only $\eta_{\mathrm{RE}}=30 / 165=0.18$. Figure 2 shows the dependence of $\eta_{\mathrm{RE}}$ on the recycling rate. It can easily be seen that increasing the collection and recycling rate from 45 to $100 \%$ would increase the energy efficiency of the use of $\mathrm{Al}$ cans by a wide margin and that the increase in energy efficiency is non-linear such that it increases the more steeply the higher the recycling rate. New battery grids. The author has developed a new process to manufacture grids for lead-acid batteries which can be minimised in weight and maximised in corrosion resistance compared to present grids. The process is based on electroforming instead of casting. ${ }^{2,15)}$ As this technology is still under development only roughly estimated data can be given for calculating prospectively the efficiency parameters to be analysed. Two basic facts can be noted: the new grids are expected to permit reducing the weight of positive grids from 50 to $30 \mathrm{~g}$ and to prolong the calendar life time of batteries from 3 to 5 years, respectively.

In terms of eco-compatibility assessment we are considering an optimum technical performance in the materials and parts design stage, i.e. matrix element 1.2. The first target parameter is the material efficiency in production, i.e. matrix element 2.4. In quantitative terms the material efficiency is raised from the present $\eta_{\mathrm{RM}}=30 \mathrm{~g} / 50 \mathrm{~g}=0.6$ to future $\eta_{\mathrm{RM}}$ $=30 \mathrm{~g} / 30 \mathrm{~g}=1$, by definition. In addition we are considering again element 1.2 regarding the improved corrosion resistance and ensuing result of battery life, i.e. application of the product, matrix element 5.2. The increase in battery life from 3 to 5 years is expressed in technical performance efficiency $\eta_{\mathrm{TT}}=3 \mathrm{y} / 5 \mathrm{y}=0.6$ which increases to $\eta_{\mathrm{TT}}=1$, by definition again. Obviously, any intermediate value can be evaluated in order to assess the progress of the development under aspects of eco-compatibility. 


\section{Acknowledgement}

I am grateful to my Japanese colleagues involved in the ecomaterials field who have attracted my attention to this fascinating topic. They have challenged me to develop the concept described in this paper.

\section{REFERENCES}

1) E. U. v. Weizsäcker: Frankfurter Allgemeine Zeitung 5. Oktober 2000.

2) H. Warlimont: Proc. Int. Symp. Environment Conscious MaterialsEcomaterials, H. Mostaghazi ed., Canadian Institute of Mining, Metallurgy and Petroleum, Montreal (2000) 399-407.

3) ISO 14040 Environmental management-Life cycle assessment-Principles and framework (1997).

4) P. Hawken, A. Lovins and H. Lovins: Natural Capitalism. Little, Brown Co., Boston (1999).
5) E. Hornbogen: Proc. Int. Conf. Recovery, Reycling, Re-Integration, 4th to 7th February 1997, Geneva, Switzerland.

6) K. Halada and R. Yamamoto: MRS Bull. 11/2001, 871.

7) M. F. Ashby: Am. Soc. Test. Meas. Stand. Techn. Publ. 1311, 1997, 45-62.

8) Mater. Trans. 43 (2002) 281-397.

9) Proceedings of the Fifth International Conference on Ecobalance, Practical tools and thoughtful principles for sustainability, 6th to 8th November 2002, Tsukuba, Japan.

10) H. Warlimont: to be published.

11) K. Halada: Proc. 2nd Int. Workshop on ECOMATERIALS, 5th to 8th Nov. 2002, Tsukuba.

12) M. Iffert, R. Ganther and J. Opgen-Rhein: Erzmetall 55 (2002) 479488.

13) Erzmetall 55 (2002) 434.

14) M. Ootani, T. Onoye and M. Miyazaki: Proc. 5th Int. Conf. Ecobalance, 6th to 8th Nov. 2002, Tsukuba, Japan.

15) H. Warlimont: Batteries International 47 (2001) 41-49. 